Journal An-Nafs: Kajian Penelitian Psikologi https://ejournal.iai-tribakti.ac.id/index.php/psikologi e-ISSN: 2549-6166 p-ISSN: 2528-0600 DOI: $10.33367 /$ psi.v5i2.1136

$\begin{array}{cccc}\text { Submitted: } & \text { Revised: } & \text { Accepted: } & \text { Published: } \\ 01-05-2020 & 12-05-2020 & 26-06-2020 & 01-12-2020\end{array}$

\title{
RELIGIOUS ATTITUDE DENGAN PERILAKU PROSOSIAL PADA RELAWAN PMI KOTA SURABAYA
}

\author{
Andari Nur Rahmawati ${ }^{1}$, Rizma Fithri ${ }^{2}$ \\ 1andarirahma80@gmail.com, 2rizmafpk@uinsby.ac.id \\ UIN Sunan Ampel Surabaya
}

\begin{abstract}
Prosocial behavior in individuals is one of the social competencies that volunteers must possess to encourage positive social interaction. Prosocial behavior by volunteers reflects a commendable social act. One of the factors that influence prosocial behavior is religion. The purpose of this study was to determine the relationship between religious attitudes with prosocial behavior in KSR PMI Surabaya City. This research is correlational in quantitative research. This research uses the scale of religious attitude and prosocial behavior scale. The number of subjects in the study $N=80$ of the total population of 400 members of the KSR PMI Surabaya City through a purposive sampling technique. Hypothesis testing in this study uses product-moment with the help of SPSS. The result of this study indicates there is a relationship between religious attitudes with prosocial behavior in KSR PMI Surabaya City. ( $r=0.653$, $p=0.000<0.05)$. This hypothesis in this study accepted that religious attitude correlates with prosocial behavior in KSR PMI Surabaya City. It means that the higher the religious attitude in KSR PMI Surabaya City, the higher the prosocial behavior. This research carried out to give an idea of the importance of having prosocial behavior not only for volunteers but for all individuals, considering that individuals are social creatures
\end{abstract}

Keyword : Religious Attitude, Prosocial Behavior, KSR PMI, Volunteer

\begin{abstract}
Abstrak
Perilaku prososial pada individu merupakan salah satu kompetensi sosial yang harus dimiliki relawan agar mendorong interaksi sosial yang positif. Perilaku prososial yang dilakukan relawan mencerminkan suatu tindakan sosial yang terpuji. Salah satu faktor yang mempengaruhi perilaku prososial adalah religious. Tujuan penelitian ini adalah untuk mengetahui hubungan antara religious attitude dengan perilaku prososial pada Korps Sukarela (KSR) PMI Kota Surabaya. Penelitian ini merupakan jenis penelitian kuantitatif korelasional. Alat pengumpulan data dalam penelitian ini menggunakan skala religious attitude dan skala Perilaku Prososial. Jumlah subjek dalam penelitian $\mathrm{N}=80$ dari total populasi 400 anggota KSR PMI Kota Surabaya melalui teknik purposive sampling. Uji hipotesis menggunakan product moment dengan bantuan SPSS. Hasil penelitian ini menunjukkan bahwa terdapat hubungan antara religious attitude dengan Perilaku Prososial Pada KSR PMI Kota Surabaya ( $r=0.653, p=0.000<0.05)$. Dengan demikian hipotesis dalam penelitian ini diterima yang artinya terdapat hubungan positif antara religious attitude dengan Perilaku Prososial pada KSR PMI Kota Surabaya. Artinya, semakin tinggi religious attitude pada KSR PMI Kota Surabaya, maka akan semakin tinggi pula Perilaku Prososial yang dirasakan. Dilakukan penelitian ini adalah memberi gambaran pentingnya memiliki jiwa perilaku prososial tidak hanya untuk relawan tetapi bagi seluruh individu, mengingat individu adalah makhluk sosial.
\end{abstract}

Kata Kunci : Religious Attitude, Perilaku Prososial, KSR PMI, Relawan 


\section{PENDAHULUAN}

Perilaku prososial merupakan bekal yang akan dibutuhkan dalam kehidupan bermasyarakat untuk menyesuaikan diri agar dapat diterima sesuai norma yang berlaku. Kehidupan bermasyarakat dalam menolong muncul secara spontan ketika melihat orang lain yang membutuhkan bantuan. Sayangnya hanya beberapa individu yang memiliki sikap untuk menolong dan cenderung mengabaikan. Perilaku prososial dikalangan masyarakat cenderung menurun dan apatis pada hal-hal yang terjadi disekelilingnya (Wisudiani \& Fardana, 2014).

Bertolak belakang dari hal tersebut, Berdasarkan hasil survei Internasional dari CAF World Giving Index 2018, Indonesia menduduki rangking pertama sebagai negara paling dermawan di dunia. Rangking tersebut dapat mengalahkan negara Selandia Baru dan Australia. Indonesia unggul dengan menunjukkan partisipasi atas nilai-nilai kemanusiaan dibuktikan dengan menolong orang asing sebesar 46\%, kegiatan menyumbang untuk amal sebesar 78\% dan berpartisipasi dalam relawan sebesar 53\% (CAF World Giving Index, 2018).

Setiap manusia pada hakikatnya ditakdirkan untuk hidup bersama dan membutuhkan interaksi antara individu satu dengan yang lainnya. Mereka tidak bisa lepas dan saling bergantung antara sesama, dengan kata lain manusia bisa disebut sebagai mahkluk sosial. Manusia dalam menjalani kehidupanya tentu melakukan berbagai macam aktivitas, salah satu aktivitas tersebut adalah melakukan tindakan sosial. Tindakan sosial dianggap adalah suatu hal yang memiliki banyak manfaat dan merupakan suatu perilaku yang terpuji. Tindakan sosial yang ditandai dengan tindakan sukarela yang direncanakan dan menguntungkan orang lain disebut dengan perilaku prososial (Afolabi, 2014).

Bentuk nyata perilaku prososial yang dilangsirkan dari (https://www.timesindonesia.co.id), KSR-PMI Unit Unisma Malang pada tanggal 02 Mei 2019 menyelenggarakan aksi untuk membantu mengadakan kegiatan donor darah sebagai bentuk kepedulian terhadap sesama. KSR PMI juga mengadakan kegiatan penyuluhan dengan tema "pupuk solidaritas dalam membantu sesama" disamping kegiatan donor darah.

Eisenberg et al. (2007) mengatkan bahwa perilaku prososial merupakan perilaku yang dilakukan secara sukarela dan memiliki tujuan untuk menolong serta menguntungkan orang lain. Perilaku prososial mempunyai dampak bagi orang yang ditolong maupun diri sendiri. Pada dampak yang dirasakan oleh orang yang ditolong adalah memenuhi kebutuhan akan perihal yang dibutuhkan. Sedangkan dampak yang dirasa oleh diri sendiri yakni memiliki perasaan bahagia, puas dan selain itu terbebas dari rasa bersalah. Perilaku prososial terdiri atas cooperating, sharing, helping, emphaty dan donating. Perilaku 
prososial dapat diartikan juga sebagai kesukarelaan dan tindakan-tindakan yang disengaja untuk memberikan manfaat dan hasil yang positif bagi penerimanya, serta terlepas tidak berdampak ataupun malah menguntungkan bagi pihak pemberi Grusec, Davidov \& Lundel dalam Elhafiz dkk, 2018).

Terdapat faktor yang mempengaruhi perilaku prososial diantaranya faktor internal dan eksternal. Faktor internal berupa personality traits, values and goals dan religious. Sedangkan faktor eksternal berupa suasana hati, modeling, dan lingkungan. Pada faktor personality traits ditemukan bahwa terdapat hubungan yang positif pada perilaku prososial di kepribadian extraversion, agrebeeableness, conscientiousness dan opennes. Sedangkan pada kepribadian neuroticism tidak memiliki hubungan yang positif terkait dengan perilaku prososial (Wisudiani \& Fardana, 2014).

Pada faktor values and goals yang mana individu mempunyai nilai moral dan tanggung jawab untuk orang lain dalam berperilaku prososial. Penalaran moral dianggap dapat memandu dalam berperilaku prososial sebagai wujud pertanggung jawab sosialnya. Individu yang memiliki penalaran moral yang tinggi maka memiliki kecenderungan hati untuk bertindak secara prososial. Mengingat penalaran moral merupakan prediktor terhadap tindakan yang dilakukan yang melibatkan moral (Lestari \& Partini, 2015).

Beberapa penelitian menemukan bahwa religious sebagai penentu dalam pentingnya dalam perilaku prososial meliputi membantu orang lain (Dwi Haryati, 2013; Muryadi \& Matulessy, 2012; Yahya \& Abidin, 2018). Religious dipercaya dapat memfasilitasi tindakan yang bermanfaat bagi orang lain dan hal yang berkaitan dengan kebajikan. Ajaranajaran agama juga menekankan pentingnya memiliki perilaku prososial dan kooperatif. Religious dipandang sebagai interpretasi dari pribadi yang mana dikaitkan dalam kepercayaan beragama sampai sikap beragama (Guo et al., 2018). Percaya pada Tuhan dapat menumbuhakan kewajiban moral yang akan terinternalisasi untuk dapat mendorong perilaku prososial (Johson et al., 2010). Berdasarkan penelitian (Yahya \& Abidin, 2018) terkait hubungan antara religiusitas dengan itensi prososial. Ditemukan bahwa terdapat hubungan yang positif antara religiusitas dengan itensi prososial. Semakin tinggi religiusitas yang dimiliki maka semakin tinggi pula intensi prososial.

Penelitian oleh Hermawati et al. (2016) menjelaskan bahwa terjadi perselisihan antar pemeluk agama dibandung sebesar 17,2 meliputi perselisihan dengan etnis lain dengan membawa agama masing-masing, terganggu dengan kegiatan keagamaan dan perbedaan kepercayaan. Berbagai ajaran agama (Islam, Kristen, Budha dll) tidak menganjurkan untuk memberi penilaian yang negatif kepada agama lain. Secara sosial, 
orang yang beragama menjalankan prinsip agama masing-masing, menjaga kedamaian ditengah masyarakat dan meningkatkan nilai-nilai kebaikan (Alimin \& Musthofa, 2019).

Berdasarkan kajian literatur lainnya oleh Schumann (2020) melalui meta analisa memaparkan bahwa lebih banyak individu yang memiliki sikap beragama cenderung lebih beramal, menjadi sukarelawan, berempati, pemaaf, saling membantu dan kooperatif. Selain itu mereka juga cenderung kurang agresif dan sedikit terlibat dalam kriminal. Sehingga konsep dalam keagamaan menguatkan serta mengarahkan invidiu pada perilaku prososial.

Menurut Jalaluddin (2010) pada buku psikologi agama yang ditulis mengungkap bahwa religious attitude merupakan hasil dari proses berpikir, merasa serta bertindak terhadap motif-motif tertentu oleh individu dengan masalah-masalah yang menyangkut hubungan dengan agama. Hubungan yang dimaksud berupa proses, sebab dan pembentukan sikap berdasarkan hasil belajar dari pengalaman yang telah diperoleh. Terdapat tiga aspek yang diambil berdasarkan kompeonen dari attitude yakni komponen kognitif, komponen, afektif dan komponen konasi.

Naami et al. (2020) mengemukakan bahwa terdapat hubungan yang positif antara religious atttitude dengan perilaku prososial pada mahasiswa kedokteran dan mahasiswa perawat. Selain itu, peran religious attitude dalam memprediksi perilaku prososial, dianggap dapat digunakan dalam intervensi untuk mempromosikan perilaku prososial di mahasiswa kedokteran dan perawat. Dijelaskan dalam sikap beragama, bahwa perilaku membantu orang lain dan belas kasih adalah salah satu kunci dari perilaku prososial.

Pada penelitian oleh Yektayar et al. (2012) mengemukakan bahwa individu yang memiliki religious attitudes dengan komponen kognitif, afektif dan konatif memiliki tingkat keadilan organisasi yang tinggi. Hal serupa juga dikemukakan bahwa, memiliki pengetahuan serta prinsip agama yang tinggi semakin tinggi pula pemahaman keadilan berorganisasi terutama pada komitmen. Sehingga, apabila religious attitude individu tinggi maka memungkinkan dapat dipastikan untuk memiliki nilai yang tinggi pada variabel perilaku prososial. Sebaliknya, apabila religious attitude individu rendah, bisa dipastikan memiliki nilai yang rendah pada variabel perilaku prososial.

Berdasarkan latar belakang yang telah dipaparkan diatas, maka fenomena perilaku prososial masih menarik untuk diteliti karena terjadi berbagai subjek didalam dan luar negeri. Penelitian ini dapat memberikan sumbangan pemikiran dan referensi bagi keilmuan psikologi, khususnya psikologi sosial dan agama. Maka hipotesis yang dapat diajukan dalam penelitian ini adalah : "terdapat hubungan antara religious attitude dengan perilaku prososial pada relawan PMI Kota Surabaya". 


\section{METODE}

Subjek dari penelitian ini adalah KSR PMI Kota Surabaya yang merupakan relawan dibawah naungan PMI Kota Surabaya. Peneliti tertarik memfokuskan pada relawan, khususnya pada anggota KSR PMI Kota Surabaya. KSR PMI dianggap lebih cepat menanggapi hal yang terkait dengan perilaku prososial, cara menolong KSR PMI lebih terarah karena dibekali dengan pengetahuan berdasarkan kompetensi masing-masing selama menjadi relawan. Selain itu, menggunakan pendekatan persuasif kepada orang yang ditolong. Anggota KSR PMI Kota Surabaya terdiri atas KSR Markas Kota Surabaya dan KSR PMI Unit Univeristas yang ada di Surabaya. Populasi dalam penelitian ini berjumlah 400 orang. Sampel subjek dalam penelitian ini sebanyak 80 orang KSR PMI Kota Surabaya.

Teknik pengambilan sampel yang digunakan adalah menggunakan purpose sampling yakni teknik menentukan sampel berdasarkan kriteria yang telah ditentukan (Sugiyono, 2013). Adapun kriteria yang ditentukan sebagai berikut : 1) berusia antara 18 sampai 30 tahun; 2) bergabung dengan KSR PMI Kota Surabaya; 3)mempunyai pengalaman bertugas.

Penelitian ini menggunakan dua alat ukur yaitu untuk mengukur religious attitude yang dimodifikasi dari skala religious attitude yang disusun oleh Hajar (2015) yang mengacu pada aspek-aspek yang dikemukan oleh Jalaluddin (2010) yakni komponen kognitif, afektif dan konasi. Pada skala religious attitude terdiri dari 20 aitem dengan koefisien reliabilitas sebesar 0.929 .

Sedangkan untuk skala perilaku prososial disusun sendiri oleh peneliti yang mengacu pada aspek-aspek yang dikemukan oleh Eisenberg et al. (2007) yakni cooperating, sharing, helping, emphaty dan donating. Pada skala perilaku prososial terdiri dari 17 aitem dengan koefidien reliabilitas 0.913 .

\section{PAPARAN HASIL}

Berikut ini dipaparkan blue print skala perilaku prososial dan relugiou attitude sebagai berikut :

Tabel 1

Blue print Skala Perilaku Prososial

\begin{tabular}{clccc}
\hline \multirow{2}{*}{ Aspek } & \multicolumn{1}{c}{ Indikator } & \multirow{2}{*}{ Total } \\
\cline { 2 - 3 } Sharing (berbagi) & $\begin{array}{l}\text { Saling berbagi informasi, } \\
\text { pengalaman atau hal-hal positif }\end{array}$ & 1,9 & 17 & \\
& $\begin{array}{l}\text { bersedia } \\
\text { curahan hati mendengarkan }\end{array}$ & 2 & 10 & 5 \\
\hline $\begin{array}{l}\text { Cooperating } \\
\text { (bekerjasama) }\end{array}$ & $\begin{array}{l}\text { Memiliki keterlibatan antar } \\
\text { kelompok }\end{array}$ & 3,11 & 18 & 6 \\
\hline
\end{tabular}


Andari Nur Rahmawati \& Rizma Fithri | Religious Attitude

\begin{tabular}{|c|c|c|c|c|}
\hline & $\begin{array}{l}\text { Kesediaan untuk bekerjasama } \\
\text { dengan orang lain }\end{array}$ & 6,22 & 13 & \\
\hline \multirow[t]{2}{*}{ Helping (menolong) } & $\begin{array}{l}\text { Memberikan bantuan kepada } \\
\text { orang lain baik yang dikenal } \\
\text { maupun tidak dikenal }\end{array}$ & $4,5,20$ & - & \multirow[t]{2}{*}{5} \\
\hline & Meringankan beban orang lain & 12,14 & - & \\
\hline $\begin{array}{c}\text { Donating } \\
\text { (meyumbang) }\end{array}$ & $\begin{array}{lr}\text { Sikap suka beramal atau } \\
\text { menyumbang barang dan jasa } \\
\text { kepada orang yang } \\
\text { membutuhkan } & \text { tanpa } \\
\text { mengharapkan imbalan } & \\
\end{array}$ & 15,21 & 7 & 3 \\
\hline Empathy & $\begin{array}{l}\text { Memahami perasaan dan } \\
\text { merespon perhatian orang lain }\end{array}$ & $8,16,19$ & - & 3 \\
\hline & Total & & & 22 \\
\hline
\end{tabular}

Tabel 2

Blue print Skala Religious Attitude

\begin{tabular}{|c|c|c|c|c|}
\hline \multirow{2}{*}{ Aspek } & \multirow{2}{*}{ Indikator } & \multicolumn{2}{|c|}{ No. Item } & \multirow{2}{*}{ Total } \\
\hline & & $\mathbf{F}$ & UF & \\
\hline \multirow{3}{*}{ Komponen Kognitif } & $\begin{array}{l}\text { Memiliki kesadaran dalam } \\
\text { beragama. }\end{array}$ & 1,10 & 17 & \multirow{3}{*}{6} \\
\hline & $\begin{array}{l}\text { Percaya dan yakin agama yang } \\
\text { dianut benar. }\end{array}$ & 2 & - & \\
\hline & $\begin{array}{l}\text { Memiliki pengetahuan yang baik } \\
\text { terkait agama }\end{array}$ & 2,18 & - & \\
\hline \multirow{3}{*}{ Komponen Afektif } & $\begin{array}{lll}\begin{array}{l}\text { Perasaan } \\
\text { beribadah }\end{array} & \text { tentram } & \text { ketika } \\
\end{array}$ & 4,12 & - & \multirow[t]{3}{*}{7} \\
\hline & Keinginan beribadah & 5 & 13 & \\
\hline & $\begin{array}{l}\text { Keyakinan akan terkabul } \\
\text { doanya }\end{array}$ & 6,19 & - & \\
\hline \multirow{4}{*}{ Komponen Konatif } & $\begin{array}{l}\text { Keteraturan } \text { Beribadah dan } \\
\text { beramal }\end{array}$ & $\begin{array}{c}7,14,2 \\
3 \\
\end{array}$ & - & \multirow[t]{3}{*}{9} \\
\hline & Mengkaji ajaran agama & $\begin{array}{c}8,15,2 \\
0 \\
\end{array}$ & - & \\
\hline & Mengamalkan ajaran agama & 9,22 & - & \\
\hline & Total & & & 20 \\
\hline
\end{tabular}

Jumlah subjek yang diteliti baik dari skala religious attitude maupun perilaku prososial adalah 80 orang. Berdasarkan demografi responden dijelaskan sebagai berikut : 
Tabel 3

Demografi Subjek

\begin{tabular}{|c|c|c|c|c|c|c|c|c|c|c|c|c|}
\hline \multirow[t]{3}{*}{ Variabel X Y } & \multicolumn{12}{|c|}{ Demografi } \\
\hline & \multicolumn{2}{|c|}{$\begin{array}{c}\text { Jenis } \\
\text { kelamin }\end{array}$} & \multicolumn{6}{|c|}{ Usia } & \multicolumn{4}{|c|}{ Pendidikan Terakhir } \\
\hline & $\mathbf{L}$ & $\mathbf{P}$ & 18 & 19 & 20 & 21 & 23 & 25 & 26 & SMA & Diploma & Sarjana \\
\hline $\begin{array}{l}\text { Religious } \\
\text { attitude }\end{array}$ & 68 & 71 & 68,8 & 72,7 & 69,1 & 67,3 & 73,7 & 75 & 65,5 & 70,2 & 72,8 & 70,3 \\
\hline prososial & 57,6 & 58,6 & 58,6 & 59,7 & 57,8 & 57,3 & $58,7 \quad 56,7$ & 55 & 50,5 & 58,7 & 58,6 & 58,3 \\
\hline \multirow[t]{3}{*}{ Variabel X Y } & \multicolumn{12}{|c|}{ Demografi } \\
\hline & \multicolumn{12}{|c|}{ Asal KSR PMI } \\
\hline & Marka & Surabaya & $\mathrm{U}$ & IAR & ITS & UNDIKA & STIKOM & SHT & & NUSA & UNIPA & UWP \\
\hline $\begin{array}{l}\text { Religious } \\
\text { attitude }\end{array}$ & & 70 & & 9 & 66,8 & 70 & 71 & 76 & & 70,3 & 69,7 & 68,7 \\
\hline prososial & & 7,7 & & 3,9 & 62,4 & 57,7 & 59 & 66,8 & & 57,4 & 44,8 & 57,7 \\
\hline \multirow[t]{3}{*}{ Variabel X Y } & \multicolumn{12}{|c|}{ Demografi } \\
\hline & \multicolumn{12}{|c|}{ Alasan Bergabung } \\
\hline & \multicolumn{2}{|c|}{$\begin{array}{l}\text { Menambah } \\
\text { pengetahuan } \\
\text { /wawasan }\end{array}$} & \multicolumn{2}{|c|}{$\begin{array}{l}\text { Mengasah jiwa } \\
\text { sosial dan soft } \\
\text { skill }\end{array}$} & \multicolumn{2}{|c|}{$\begin{array}{l}\text { Menambah } \\
\text { relasi }\end{array}$} & $\begin{array}{l}\text { Mengisi } \\
\text { waktu } \\
\text { luang }\end{array}$ & \multicolumn{4}{|c|}{$\begin{array}{c}\text { Mengasah rasa kemanusia mengingat } \\
\text { KSR PMI adalah organiasai relawan } \\
\text { yang siap sedia menolong }\end{array}$} & Lainya \\
\hline $\begin{array}{l}\text { Religious } \\
\text { attitude }\end{array}$ & \multicolumn{2}{|c|}{70,59} & \multicolumn{2}{|c|}{70,06} & \multicolumn{2}{|r|}{70,6} & 69,67 & \multicolumn{4}{|c|}{70,72} & 75,25 \\
\hline prososial & \multicolumn{2}{|c|}{58,20} & \multicolumn{2}{|c|}{58,17} & \multicolumn{2}{|r|}{58,21} & 58,47 & \multicolumn{4}{|c|}{58,39} & 62 \\
\hline
\end{tabular}

Yang pertama yakni demografi responden berdasarkan jenis kelamin. Diketahui banyaknya data responden dari jenis kelamin laki-laki sebanyak 18 orang dengan nilai mean pada perilaku prososial sebesar 57,6. Sedangkan dari jenis kelamin perempuan sebanyak 62 orang dengan nilai mean pada perilaku prososial sebesar 58,6.

Yang kedua yakni demografi responden berdasarkan usia. Diketahui banyaknya data responden dari usia 18 tahun sampai dengan 26 tahun. Sebagian besar responden berusia 19 tahun sebanyak 27 orang, dengan nilai mean pada perilaku prososial sebesar 59,7 .

Yang ketiga yakni demografi responden berdasarkan pendidikan terakhir. Diketahui banyaknya data responden dari lulusan SMA, Diploma dan Sarjana. Sebagian besar responden berasal dari lulusan SMA dan sedang menempuh perkuliahan sebanyak 60 orang. Sedangkan nilai mean pada perilaku prososialnya sebesar 58,7.

Yang keempat yakni demografi responden berdasarkan asal. Diketahui banyaknya data responden berasal dari KSR PMI Markas surabaya, unit KSR PMI UNAIR, unit KSR PMI ITS, unit KSR PMI UNDIKA, unit KSR PMI STIKOM, unit KSR PMI STIKES Hang Tuah, unit KSR PMI UNUSA, unit KSR PMI UNIPA dan unit KSR PMI UWP. Sebagian besar responden berasal dari KSR Markas Suarabaya. Nilai mean terbesar pada perilaku prososial berasal dari KSR PMI STIKES Hang Tuah sebesar 66,8.

Yang kelima yakni demografi responden berdasarkan alasan bergabung. Diketahui banyaknya data responden memiliki alasan bergabung antara lain : menambah pengetahuan/wawasan, mengasah jiwa sosial dan soft skill, menambah relasi, mengisi 
waktu luang, mengasah rasa kemanusia mengingat KSR PMI adalah organiasai relawan yang siap sedia menolong dan lainnya. Nilai mean terbesar pada perilaku prososial beralasan lainnya diantaranya bercita-cita sebagai relawan, mendapat hal baru yang bermanfaat, untuk mengabdi, agar hidup tidak sia-sia karena perbuatan akan dipertanggung jawabkan di akhirat sebesar 62 .

Berdasarkan analisa data yang telah dilakukan, diperoleh deskripsi data antara variabel religious attitude dengan perilaku prososial sebagai berikut :

\section{Tabel 4}

\section{Deskripsi Data Statistik Variabel}

\begin{tabular}{cccccc}
\hline Variabel & $\mathbf{N}$ & $\begin{array}{c}\text { Nilai } \\
\text { Min. }\end{array}$ & $\begin{array}{c}\text { Nilai } \\
\text { Max. }\end{array}$ & Mean & Std. \\
\hline Religious Attitude & 80 & 55 & 80 & 70,61 & 6,43 \\
\hline Perilaku Prososial & 80 & 50 & 68 & 58,34 & 4,65 \\
\hline
\end{tabular}

Berdasarkan tabel 2 diatas, jumlah keseluruhan responden sebanyak 80 orang. Pada variabel religious attitude memiliki nilai minimum sebesar 55 , nilai maximum sebesar 80 , mean sebesar 70,61 dan standar deviasi sebesar 6,43. Sedangkan pada variabel perilaku prososial memiliki nilai minimum sebesar 50 , nilai maximum sebesar 68 , mean sebesar 58,34 dan standar deviasi sebesar 4,65.

Sementara itu, kategorisasi religious attitude dan perilaku prososial dibagi menjadi tiga kategori (rendah, sedang dan tinggi). Pada variabel religious attitude sebanyak 17 responden dalam kategori rendah, 49 responden termasuk dalam kategori yang sedang dan 14 responden dalam kategori tinggi. Sedangkan pada variabel perilaku prososial sebanyak 12 responden dalam kategori rendah, 51 responden termasuk dalam kategori yang sedang dan 17 responden dalam kategori tinggi.

Dilakukan uji asumsi sebelum dilakukannya uji analisa. Pada uji normalitas diperoleh nilai Kolmogrorv-Smirnov sebesar 0, 75 dengan signifikasi $p=0,200(p>0,05)$. Dari hasil tersebut menunjukkan bahwa residual memiliki data yang berdistrubusi normal. Pada uji linieritas antara variabel religious attitude dengan perilaku prososial mendapat hasil $\mathrm{F}=1,28$ dengan signifikasi 0,23 ( $\mathrm{p}>0.05$ ). terpenuhinya uji asumsi pada kedua variabel dapat dilakukan uji hipotesis menggunakan product moment.

Berdasarkan hasil perhitungan korelasi $\mathrm{r}$ product memonet diketahui bahawa ada hubungan positif anatara religious attitude dengan perilaku prososial. Berikut dijelaskan pada tabel dibawah ini : 
Tabel 5

Hasil analisis korelasi pearson

\begin{tabular}{ccc}
\hline Variabel & $\boldsymbol{r x y}$ & Sig. \\
\hline $\begin{array}{l}\text { Religious Attitude- } \\
\text { Perilaku prososial }\end{array}$ & 0,653 & 0,000 \\
\hline
\end{tabular}

Dari tabel diatas, menunjukkan bahwa nilai koefisien perason correlation religious attitude dan perilaku prososial sebesar $r x y=0,653$ dengan signifikasi $\mathrm{p}=0,000(\mathrm{p}<0,005)$. Maka terdapat hubungan positif antara religious attitude dengan perilaku prososial dan hipotesis diterima. Artinya semakin tinggi religious attitude maka semakin tinggi pula perilaku prososial.

\section{PEMBAHASAN}

Dari penelitian yang telah dilakukan, menunjukan bahwa religious attitude memiliki hubungan dengan perilalu prososial pada KSR PMI Kota Surabaya. Diperoleh hasil jika religious attitude memiliki hubungan yang signifikan dan memilki taraf yang sedang dengan variabel perilaku prososial. Hal tersebut sesuai dengan nilai signifikasi pada analis korelasi $p=0,000(p>0.05)$ sehingga hipotesi yang diajukan diterima dan terdapat hubungan yang positif. Semakin tinggi religious attitude maka semakin tinggi pula perilaku prososial. Sebaliknya, semakin rendah religious attitude maka semakin rendah pula perilaku prososial.

Menurut Jalaluddin (2010), individu dianggap mempunyai religious yang tinggi apabila memiliki keterikatan religious yang lebih besar sehingga individu mematuhi serta menjalankan ajaran dan kewajiban agamanya dengan semestinya. Oleh sebab itu, individu yang mempunyai tingkat religious yang tinggi tidak hanya mematuhi perintah agama seperti rukun islam yang meliputi sholat, zakat dan puasa tetapi juga menjalin hubungan yang baik dengan orang lain. Contoh dari menjalin hubungan yang baik dengan orang lain dapat seperti membantu orang lain, menolong, bekerja sama dan meyumbang yang mana termasuk dalam aspek-aspek perilaku prososial.

Orang yang memiliki religious yang tinggi akan cenderung memiliki sifat menolong terhadap individu lain dalam jangka panjang (Myers, 2012). Hal ini sesuai dengan dalam penelitian Yahya \& Abidin (2018) menyimpulkan bahwa adanya hubungan yang positif dan signifikan antara religiusitas dengan intensi perilaku prososial pada siswa. Siswa-siswa cenderung memiliki sikap seperti berbagi, menolong, kerjasama, dan beramal kepada orang disekitarnya baik teman maupun guru.

Pada penelitian ini menjelaskan bahwa relawan yang mempunyai religious attitude yang baik tercermin dari ketaatan dalam beragama berdasarkan aspek kognitif, afeksi dan 
konasi yang dimiliki. Aspek kognitif tercermin bahwa memiliki pengetahuan yang baik terkait agama serta aspek afektif adanya perasaan untuk menjalankan ibadah. Pada aspek konasi tercermin bahwa mengamalkan ajaran agama, terimplementasi dengan berbagi dan menolong terhadap orang lain. Dengan demikian, relawan yang memiliki ketaatan beragama yang tinggi, akan cenderung memiliki perilaku prososial yang tinggi pula. Sehingga faktor religious berperan penting sebagai pendorong perilaku prososial seperti berbagi (sharing), menolong (helping), kerjasama (cooperating), beramal (donating) dan empati.

Hasil penelitian ini sejalan dengan penelitian sebelumnya yang dilakukan oleh Naami et al. (2020) yang membuktikan terdapat hubungan positif antara religious atttitude dengan perilaku prososial pada mahasiswa kedokteran dan mahasiswa perawat. Tak hanya itu, peran religious attitude dianggap dapat digunakan dalam intervensi untuk mempromosikan perilaku prososial di mahasiswa kedokteran dan perawat. Dijelaskan dalam sikap beragama, bahwa perilaku membantu orang lain dan belas kasih adalah salah satu kunci dari perilaku prososial. Bigdeloo \& Bozorgi (2016) memiliki kesamaan bahwa religion memainkan peran penting dalam aspek kehidupan individu maupun sosial. Selain itu religious attitude dan keyakinan beragama mempengaruhi komponen kognitif atas peristiwa dan pemikiran dalam kehidupan.

Pada penelitian oleh Yektayar et al. (2012) menemukan individu yang memiliki religious attitudes dengan komponen kognitif, afektif dan konatif memiliki tingkat keadailan organisasi yang tinggi. Hal serupa juga dikemukakan bahwa, memiliki pengetahuan serta prinsip agama yang tinggi semakin tinggi pula pemahaman keadilan berorganisasi terutama pada komitmen. Jadi terdapat perbedaan penelitian antara Yektayar et al. (2012) dengan Naami et al. (2020). Yektayar et al. (2012) menggunakan keadalilan organisasi sedangkan Naami et al. (2020) menggunakan perilaku prososial. Sehingga, apabila religious attitude tinggi maka memungkinkan dapat dipastikan untuk memiliki nilai yang tinggi pada variabel perilaku prososial. Sebaliknya, apabila religious attitude rendah, memiliki nilai yang rendah juga pada variabel perilaku prososial.

Penelitian yang dilakukan oleh Dwi Haryati (2013) mengungkap bahwa tidak cukup hanya dengan melakukan ritual keagamaan yang dianut oleh individu atau hanya memahami serta mengimplemtasikan hubungan manusia dengan tuhan untuk meningkatkan religious. Tetapi individu perlu menjalankan serta mengimplementasikan hubungan antara manusia sebagai wujud dalam mencapai tingkat ketaqwaan. Sehingga dapat terlihat korelasi antara religious denagn perilaku prososial, terutama pada agama 
islam yang mengajarkan untuk menyeimbangkan antara hubungan manusia dengan Allah serta hubungan manusia dengan sesamanya (habluminallah dan hablummninannas).

Ditemukan juga dalam penelitian ini, bahwa jenis kelamin perempuan lebih prososial dibandingkan laki-laki. Hal tersebut sejalan dengan Fikrie \& Fitriah (2019) bahwa perempuan memiliki tingkat prososial yang lebih tinggi daripada laki-laki dalam hal membantu, bekerjasama, memehami orang lain dan berbagi. Sebagian besar subjek yang memiliki prososial tinggi berumur 19 tahun. Pada usia 18-21 tahun memasuki kategori remaja akhir yang menunjukkan perilaku prososial yang tinggi. (Pitaloka \& Ediati, 2015). Pada penelitian ini subjek yang berperan lebih besar didominasi dengan relawan perempuan yang berusia antara 18-21 tahun.

Hasil data demografi berdasarkan pendidikan terkahir subjek, menyimpulkan bahwa lulusan SMA atau sedang menempuh perkuliahan memiliki tingkat prossosial yang tinggi. Hal ini sejalan dari temuan Williamson dan Clark (dalam Husna \& Fahmi, 2019) mahasiswa terbiasa memberikan pertolongan kepada orang lain lebih merasa tenang dan merasakan dirinya lebih baik seperti dapat diandalkan dibandingkan mahasiswa yang tidak memperoleh kesempatan tersebut. Sehingga pendidikan dapat mendorong perilaku prososial, tanggung jawab sosial serta kontribusi sosial. Selain itu KSR PMI Kota Surabaya yang berasal dari mahasiswa kesehatan lebih prososial daripada yang lain. Wisudiani \& Fardana (2014) ditemukan pada mahasiswa keperawatan memiliki prososial yang tinggi, karena kelak akan terjun dilapangan.

Alasan subjek bergabung dengan relawan dijelaskan karena bercita-cita sebagai relawan, mendapat hal baru yang bermanfaat, untuk mengabdi, agar hidup tidak sia-sia karena perbuatan akan dipertanggung jawabkan di akhirat. Hal tersebut sejalan dengan pendapat Kartikaningsih et al. (2016) bahwa kepercayaan religius dapat memprediksi sikap alturisme seseorang dalam jangka panjang yang diimplementasikan dalam kegiatan sukarela dan kontribusi amal. Sehingga individu berbuat prososial kepada sesamanya untuk memenuhi kebutuhan religius dan kebutuhan kemanusiaan atau menjalankan habluminallah dan hablummninannas secara seimbang.

\section{SIMPULAN}

Dari hasil penelitian yang dilakukan, dapat disimpulan bahwa terdapat hubungan positif antara religious attitude dengan perilaku prososial pada KSR PMI Kota Surabaya. Hal tersebut terlihat bahwa antara variabel religious attitude dan perilaku prososial memiliki hubungan yang signifikan. Dengan demikian hipotesis yang diajukan oleh peneliti diterima, yakni terdapat hubungan antara religious attitude dengan perilaku prososial pada KSR PMI 
Kota Surabaya. Artinya apabila semikin tinggi nilai religious attitude maka nilai perilaku prososial akan semakin tinggi pula.

\section{DAFTAR PUSTAKA}

Afolabi, 0. A. (2014). Psychosocial Predictors Of Prosocial Behaviour among a Sample of Nigerian Undergraduates. 10(2), 241-266.

Alimin, A., \& Musthofa, M. A. (2019). Hubungan antara ingroup favoritism dan perilaku prososial.3(1), 32-45.

Arikunto. (2002). Metodelogi Penelitian Suatu Pendekatan Proposal. PT. Rineka Cipta.

Bigdeloo, M., \& Bozorgi, Z. D. (2016). Relationship between the Religious Attitude, SelfEfficacy, and Life Satisfaction in High school Teachers of Mahshahr City. International Education Studies, 9(9), 58. https://doi.org/10.5539/ies.v9n9p58

CAF World Giving Index 2018. (2018). World Giving (Issue October).

Dwi Haryati, T. (2013). Kematangan Emosi, Religiusitas Dan Perilaku Prososial Perawat Di Rumah Sakit. Persona:Jurnal Psikologi Indonesia, 2(2), 162-172. https://doi.org/10.30996/persona.v2i2.109

Eisenberg, N., Fabes, R. A., \& Spinrad, T. L. (2007). Prososial Development. Handbook of Child Psychology, 73. https://doi.org/10.4324/9781315560984-2

Elhafiz, S., Nauly, M., Fauzi, R., \& Hakim, M. A. (2018). Psikologi sosial: Pengantar dalam teori dan penelitian. Salemba Humanika.

Fikrie, \& Fitriah, A. (2019). Perbedaan Perilaku Prososial pada Remaja ditinjau dari Jenis Kelamin (The Difference of Prosocial Behavior in Teenages Reviewed from Kinds of Markets). Psycho Holistic, 1(1), 18-22.

Guo, Q., Liu, Z., \& Tian, Q. (2018). Religiosity and Prosocial Behavior at National Level. Psychology of Religion and Spirituality, March. https://doi.org/10.1037/rel0000171

Hajar, R. P. (2015). Hubungan Antara Sikap Beragama dan Kecenderungan Perilaku Seksual Pranikah pada Mahasiswa. UIN Sunan Kalijaga Yogyakarta.

Hermawati, R., Paskarina, C., \& Runiawati, N. (2016). Toleransi Antar Umat Beragama di Kota Bandung.

KSR PMI Unit Unisma Gelar Diklat Lanjutan ke 29, Ini Temanya, (2019). https://www.timesindonesia.co.id/read/news/223017/ksr-pmi-unit-unismagelar-diklat-lanjutan-ke-29-ini-temanya

Husna, W., \& Fahmi, R. (2019). Hubungan Kebersyukuran Dengan Perilaku Prososial Pada Mahasiswa. Jurnal Psikologi Islam Al-Qalb Jilid 10. No 2., September.

Kartikaningsih, Suharso, A., \& Sutoyo. (2016). TIngkat Forgiveness dan Prososial antara Siswa Sekolah Umum dan Sekolah Berbasis Agama. Indonesian Journal of Guidance and Counseling: Theory and Application, 5(1), 39-44. journal.unnes.ac.id/sju/index.php/jbk

Lestari, D., \& Partini. (2015). Hubungan Antara Penalaran Moral Dengan Perilaku Prososial Pada Remaja. Jurnal Indigenous, 13(2), 41-46.

Muryadi, M., \& Matulessy, A. (2012). Religiusitas, Kecerdasan Emosi Dan Perilaku Prososial Guru. Jurnal Psikologi Tabularasa, 7(2), 126827.

Myers, D. G. (2012). Psikologi Sosial. Edisi 10. Jilid 2. (10th ed.). Salemba Humanika. 
Naami, A., Honarmand, M. M., Nejad, S. B., Amouzadeh, M. H., Asadi, A., \& Sanaeenasab, N. (2020). Relationship between Religious Attitude and Prosocial Behavior Considering the Mediating Role of Empathy and Altruism in Nursing and Medical Students. Journal Mazandaran University of Medical Sciences, 29(182), 73-81.

Pitaloka, D. A., \& Ediati, A. (2015). Rasa Syukur Dan Kecenderungan Perilaku Prososial Pada Mahasiswa Fakultas Psikologi Universitas Diponegoro. Empati: Jurnal Karya Ilmiah S1 Undip, 4(2), 43-50.

Prof. Dr. H. Jalaluddin. (2010). Psikologi Agama. PT. RajaGrafindo Persada.

Schumann, K. (2020). A Force for Good: When and Why Religion Predicts Prosocial Behavior. Journal of Moral Theology, 9(1), 34-50.

Sugiyono. (2013). Metode Penelitian Pendidikan Pendekatan Kuantitatif, Kualitatif, dan R\&D. Alfabeta.

Wisudiani, R., \& Fardana, N. A. (2014). Hubungan Antara Faktor Kepribadian Big Five dengan Perilaku Prososial pada Mahasiswa Keperawatan. Psikologi Klinis Dan Kesehatan Mental, 3 no 1(November), 2004. https://doi.org/10.1002/ejoc.201200111

Yahya, I. S., \& Abidin, Z. (2018). Hubungan Antara Religiusitas Dengan Intensi Prososial Pada Siswa-Siswi Madrasah Aliyah Muhammadiyah Kudus. Empati, 7(4), 339-344.

Yektayar, M., Tojari, F., Zareie, A., \& Mohammadi, S. (2012). The relationship between religious attitudes and perceptions of organizational justice in coaches. Scholars Research Library Archives of Applied Science Research, 4(4), 1753-1757. www.scholarsresearchlibrary.com 